\title{
Percepción ciudadana de la legitimidad democrática del régimen chávez-madurista en Venezuela; las organizaciones internacionales y la doctrina
}

\section{Socorro Márquez Regalado ${ }^{1}$ \\ Abraham Paniagua Vázquez ${ }^{2}$ \\ Román René Medrano Carrasco ${ }^{3}$ \\ José Humberto Medrano Carrasco ${ }^{4}$}

\section{Resumen}

Con el objeto de inferir si la realidad venezolana durante el periodo chávez-madurista cumple los parámetros de legitimidad y gobernabilidad democrática, en una perspectiva demoscópica de los mismos venezolanos, se cubrieron los siguientes supuestos: a) descripción del concepto de legitimidad, así como los de democracia material, formal, de origen y de funcionamiento; b) distinción de los índices de satisfacción ciudadana, en materia de estado de derecho, división de poderes, economía y derechos humanos, partiendo de las

\footnotetext{
1 Académico mexicano actualmente se desempeña como Profesor-Investigador de Tiempo Completo de la Facultad de Ciencias Políticas y Sociales de la Universidad Autónoma de Chihuahua. Con Maestría en Derecho Electoral, Licenciado en Derecho y en Filosofía, actualmente cursando el Doctorado en Derecho por la Universidad Carlos III de Madrid. Miembro de la Sociedad Mexicana de Filosofía y de la Sociedad Filosófica del Norte de México "Arche". Cuenta con el reconocimiento al perfil deseable PRODEP, otorgado por la Secretaría de Educación Pública. Universidad Autónoma de Chihuahua - México. ORCIDiD: http://orcid.org/0000-0002-1112-3247 E-mail: smarquez@uach.mx

${ }^{2}$ Académico mexicano, Doctor en Ciencias Sociales con especialidad en Política, Gobierno y Asuntos Públicos, actualmente se desempeña como Profesor-Investigador de Tiempo Completo y Director (2016 -2022) de la Facultad de Ciencias Políticas y Sociales de la Universidad Autónoma de Chihuahua. Es miembro del Sistema Nacional de Investigadores Nivel I del Consejo Nacional de Ciencia y Tecnología CONACYT, cuenta con el reconocimiento al Perfil Deseable PRODEP otorgado por la Secretaría de Educación Pública. En el año 2011 el Centro Universitario para el Desarrollo Docente de la UACH lo reconoció como Profesor Universitario Distinguido, mientras que en el 2014 la propia UACH le otorgó la Presea a la Excelencia Docente. Universidad Autónoma de Chihuahua - México. ORCID iD: https://orcid.org/0000-0002-5062-8635 E-mail: abrahampaniagua@hotmail.com

3 Académico mexicano, cuenta con dos maestrías, una en Comunicación Política y Marketing Electoral y la otra en Periodismo. Licenciado en Periodismo, actualmente se desempeña como Profesor-Investigador de Tiempo Completo de la Facultad de Ciencias Políticas y Sociales de la Universidad Autónoma de Chihuahua. Cuenta con el reconocimiento al perfil deseable PRODEP, otorgado por la Secretaría de Educación Pública. Recibió la condecoración "Distinción Profesional Colegiada 2018", que otorga la Secretaria de Educación y Deporte del Gobierno del Estado, a través de la Dirección de Profesiones. Universidad Autónoma de Chihuahua - México. ORCID iD: https://orcid.org/0000-0001-8261-8135 E-mail: rmedrano2008@hotmail.com

${ }^{4}$ Académico mexicano, Master en Mercadotecnia, actualmente se desempeña como profesor de Tiempo Completo en la Facultad de Ciencia Políticas y Sociales de la Universidad Autónoma de Chihuahua y Director del Instituto Educativo Cuauhtémoc A.C. Forma parte de un Grupo Disciplinar Comunicación, Política y Sociedad en el que sus temas de interés se refieren a ideologías, política y movimientos sociales. Autor de una antología sobre las Habilidades del Pensamiento. Ha sido ponente en Congresos Nacionales de Educación y en temas sociales, participado en Congresos Nacionales de Filosofía. Ha asesorado y/o dirigido tesis en licenciatura y maestría. Universidad Autónoma de Chihuahua - México. E-mail: medrano.jos@gmail.com
} 
herramientas cuantitativas ofrecidas por latinobarómetro.org, contrastando los resultados con análisis cualitativos de diversos instrumentos elaborados por Freedom House, Human Rights, la OEA, la CIDH, la UPLA y percepciones de académicos especializados; c) con el objeto de identificar las causas de los bemoles estadísticos encontrados, se hizo una relación de hechos históricos que coinciden temporalmente con la aplicación del instrumento, circunstancias de hecho que, presumiblemente, explicarían el porqué de los resultados. Al final del proceso, los resultados indican que, en el caso concreto analizado y desde el punto de vista de la perspectiva demoscópica explicada, no se actualiza la existencia de los elementos indispensables para que el gobierno chávez-madurista sea legítimo y materialmente democrático, conclusión que se obtiene inductivamente.

Palabras clave: Gobernabilidad democrática, estudios demoscópicos, derechos humanos, estado de derecho, división de poderes.

\section{Introducción}

Uno de los debates más significativos en la ciencia política gira en torno la gobernabilidad democrática. No es casual que el Programa para el Desarrollo de la Naciones Unidas establezca que, en el marco del fenómeno de la gobernabilidad, estén comprendidos los siguientes aspectos que a continuación planteo en forma de pregunta: ¿cómo se ejerce el poder? ¿cómo se toman las decisiones sobre temas de inquietud pública? y ¿cómo los ciudadanos articulan sus intereses, ejercitan sus derechos, cumplen sus obligaciones y median sus diferencias?

Al respecto, el dos veces Secretario General de la OEA, José Miguel Insulsa, ha planteado que, para cumplir el llamado principio democrático, es necesario conjugar las capacidades políticas de los gobernantes para diseñar y darle estabilidad a la democracia, habilidades que, por cierto, han sido puestas en duda en diversos momentos históricos en América Latina, dado la gran cantidad de disfunciones en materia democrática en los últimos 100 años.

Un breve análisis histórico muestra que en 25 países de América Latina se presentaron durante el siglo XX, 327 golpes de estado, sin contar los llamados "golpes fríos" o renuncias "voluntarias", ni las conspiraciones abortadas. Lo anterior nos da una base panorámica de la dimensión del problema. Aún sin considerar si el gobierno procede de un gobierno electo por el pueblo en un proceso democrático o de un golpe de estado, parece evidente que en la actualidad hay gobiernos que transgreden garantías o derechos que 
son concomitantes con la democracia, como la estabilidad, la paz, el desarrollo, la pobreza, el estado de derecho, el derecho al sufragio, la alternancia en el poder, la observación internacional, la división de poderes, los derechos humanos, la participación política del ciudadano, y en oposición a estos valores básicos de la democracia, se practica cada vez más el despotismo de los gobernantes.

El objeto del presente estudio de caso es conocer la percepción del venezolano, de una parte de la doctrina y de algunas instancias internacionales, sobre la actualización de los mencionados aspectos durante el periodo del "chavez-madurismo", de acuerdo con el siguiente cuestionamiento: ¿existe una crisis de legitimidad del gobierno venezolano por violar los presupuestos indispensables para que un gobierno se considere democrático? La hipótesis principal de investigación es que, a partir de la opinión de un segmento mayoritario de los venezolanos, en momentos precisos del periodo analizado, no se cumplen los postulados principales de los valores democráticos, y derivado de ello, no existe "consentimiento" de los gobernados en relación con las políticas públicas de los gobernantes, circunstancia que se pretende demostrar a partir de los estudios demoscópicos que se citarán y del estudio de las demás fuentes citadas. 


\section{Aproximaciones conceptuales}

\subsection{Relación del principio de "legitimidad" de un gobierno con el concepto de democracia material y democracia de funcionamiento.}

Es posible que la legitimidad de un gobierno se confunda con la legalidad, es decir, que se plantee una igualdad entre el cumplimiento de la norma en el proceso electoral que le dio origen, con los elementos derivados de su actuación en el ejercicio del gobierno, adquiriendo automáticamente rasgos de legitimidad por el simple hecho de haber sido electo por el pueblo en tal proceso electivo. Este criterio obvia un factor indispensable para que la legitimidad se concrete, el hecho de que dicho gobierno debe ejercerse por el bienestar de la comunidad, siendo último elemento un factor sine cuan non para que se le considere legítimo.

En este sentido, Max Weber plantea que una acción es legítima en la medida que el sujeto actúa de acuerdo a valores, los cuales puede ser, respecto de los medios como de los objetivos que se persiguen, mientras que para Carl Schmitt, el principio de legitimidad "contienen una dignidad supralegal, que se levanta por encima de toda resolución jurídica" (Oro, 2002). Por su parte Guglielmo Ferrero, en su libro "El poder. Los genios invisibles de la ciudad" considera que

\footnotetext{
“el gobierno legítimo es una forma de poder en la que no está presente el sentimiento de miedo, porque los gobernantes han aprendido finalmente a sostenerse a partir del consentimiento activo o pasivo de los gobernados y, consecuentemente, a reducir en proporción el empleo de la fuerza." (Martínez, 2009)
}

Partiendo de estas ideas sobre la legitimidad, intentamos a continuación hacer un parangón con la diferencia que se hace de los conceptos de democracia formal y material, la primera encuentra su expresión en elecciones libres, justas y la participación popular en el proceso político, y la segunda, la material, es la preferencia del término sociedad democrática sobre los otros conceptos de «democracia»o «Estado democrático», con todas sus implicaciones semánticas. (GARCÍA, 2006, pág. 75). Esta diferencia, que parece accidental, tiene una significación substancial pues nos invita a suponer que la sociedad es más amplia que el Estado, aquella incluye a esta, es decir, no se limita a valorar la democracia sólo en los órganos gubernamentales, sino en todos los componentes de la sociedad, transversalmente, lo cual nos permite abordar todos aquellos elementos de la democracia material. 
En ese mismo tenor, en palabras de Roncagliolo, citado por Jácome (2010), se puede distinguir entre democracia de origen y de funcionamiento, pues pueden existir formas democráticas, pero sin su contenido.

He aquí diversas visiones coincidentes en el fondo sobre el deber ser de los actos del gobierno para que exista legitimidad. Todo lo anterior se puede resumir de la siguiente manera: no es suficiente ser electo en un proceso electoral con mediano o alto nivel de participación y cumpliendo con las normas electorales establecidas, sino que deben existir en dicho proceso elementos de justicia y libertad para el ejercicio del voto. Más aún, dicho gobierno electo democráticamente debe actuar en razón de principios de valor, es decir, en términos supralegales, con contenido, por el bienestar social y, por supuesto, contar con el consentimiento activo o pasivo de los gobernados.

Partiendo de estos conceptos nos preguntamos ¿Existe en el periodo estudiado en Venezuela un sistema de gobierno que ejerce -o ha ejercido- la democracia en su sentido material o de funcionamiento? En otras palabras ¿Se cumplen los postulados principales de los valores democráticos? ¿Hay consentimiento del pueblo de Venezuela en torno a las acciones del gobierno chávez-madurista?

\subsection{Análisis comparativo doctrinal sobre los elementos de la gobernabilidad democrática}

Ramacciotti, enumera los elementos democráticos sine qua non que deben estar presentes en toda democracia, siendo los siguientes:

"1.- Debe ser un régimen basado en el estado de derecho, (rule of law) esto es, que tenga como marco jurídico rector a una constitución o ley suprema fundamental que expresa la voluntad popular, consignando los derechos y obligaciones de los gobernantes, de los ciudadanos, así como las instituciones del Estado y los valores fundamentales que sustentan a una nación; 2.- Que exista el derecho de sufragio para elegir y/o ser elegido para ejercer cargos públicos representando la voluntad popular en elecciones universales, periódicas, libres, multipartidarias y justas, que permitan la alternancia en el poder y, de ser el caso, con libre acceso a una observación internacional; 3.- El acceso al poder y su ejercicio respetando el estado de derecho; 4.- La subordinación de las leyes, instituciones y ejercicio de la autoridad civil legalmente constituida; 5.- La existencia de poderes separados e independientes que permitan un mutuo control y el "balance de poder"; 6.- Un poder judicial autónomo que garantice la igualdad ante la ley, el debido proceso y los derechos de todos y cada uno de los habitantes en un Estado; 7.- El ejercicio efectivo de las libertades fundamentales y el respeto a los derechos humanos básicos, civiles y políticos, en particular 
el derecho a la participación política, la libertad de expresión y la no discriminación en función de sexo, raza, credo o pensamiento. (Ramacciotti, 2009, pág. 62)

En términos semejantes, el exsecretario general de la OEA, Jesús Miguel Insulsa plantea lo que podríamos denominar los 5 grandes retos de la gobernabilidad en torno al modelo democrático:

“a) Pleno respeto de los derechos humanos; b) Mantener la vigencia del Estado de Derecho; c) Satisfacer las necesidades de las mayorías nacionales; d) Ejercer el poder legítimo de origen con elección mayoritaria sin que ello sirva de pretexto para un ejercicio antidemocrático del poder; $\mathrm{y}$, finalmente, e) Ser capaces de gobernar efectivamente, es decir, la elección democrática implicaría también tener el poder y las condiciones de regir de manera efectiva en cada país. (Insulsa, 2015, pág. 242)

Otro conjunto de parámetros de la democracia es el que plantea Agustín Basave (2000, pág. 199), para quien esta forma de organización política no es el único régimen político legítimo, sin embargo, ninguna forma de gobierno es más humana y más justa que la democracia. Estas son las siete razones para fundamentar el aserto: 1) garantiza la activa participación política del ciudadano; 2) evita el despotismo de los gobernadores; 3 ) permite la manifestación regular y ordenada de la opinión pública; 4) posibilita los virajes y reajustes convenientes y oportunos; 5) fomenta la racionalidad, y por la racionalidad la eticidad; 6) se adapta mejor a una sociedad fraccionada, con un pluralismo de valores; 7) reconoce la igualdad esencial de los hombres y favorece la estructuración y el funcionamiento del Estado de Derecho.

Robert A. Dahl, autor de amplio reconocimiento en el marco del derecho internacional, citado por Eira Ramos (2002, pág. 81) establece lo que entiende por "poliarquía":

"se deriva de las palabras griegas que significan "muchos" y "gobierno", para distinguirla del gobierno de uno (monarquía) o del gobierno de pocos (oligarquía o aristocracia); Dahl introdujo el término en 1953 para referirse a una democracia representativa moderna con sufragio universal y distinguirla a su vez tanto de las democracias representativas con sufragio restringido ( las del siglo XIX y parte del XX) como de la democracia griega y la república romana que carecían de muchas otras características como partidos políticos, derecho a formar organizaciones políticas, grupos de interés organizados, etc.”. (Ramos, 2002) 
Las 6 condiciones mínimas para que exista una poliarquía según Dahl son:

“1.- Cargos públicos electos: los ciudadanos deciden mediante elección quién asumirá la ejecución de las decisiones político-administrativas. La representatividad es una característica de los gobiernos democráticos modernos a gran escala. 2.- Elecciones libres, imparciales y frecuentes: en general, se observa poca coerción en el ejercicio de este derecho ciudadano (respecto a la imparcialidad y a la frecuencia de las elecciones volveremos más adelante cuando señalemos las observaciones que sobre esta lista hace O’Donnell). 3.- Libertad de expresión: todo ciudadano debe gozar libremente del derecho a expresar sus opiniones sobre el gobierno, el régimen, el orden socio- económico o la ideología prevaleciente, incluso si critica el ejercicio de los cargos públicos en cuya elección participó. 4.- Acceso a fuentes alternativas de información: deben existir fuentes alternativas de información que no estén bajo el control del gobierno ni de cualquier otro grupo político individual que pueda incidir sobre valores y actitudes políticas públicas; los ciudadanos deben tener acceso a ellas y las mismas han de estar protegidas por la ley. 5.- Autonomía de las asociaciones: debe garantizarse el derecho a todo ciudadano de conformar asociaciones u organizaciones relativamente independientes, incluyendo partidos políticos y grupos de interés. 6.- Ciudadanía inclusiva: todo adulto con residencia permanente en un país y sujeto a las leyes del mismo debe gozar de los mismos derechos, derechos que están contenidos en los cinco rubros precedentes. (Ramos, 2002)

En ese mismo sentido, Huntington, en su libro La Tercera Ola, trata de explicar los factores que afectan la consolidación democrática; Ramos los resume de la siguiente manera:

"al respecto expone que existen tres tipos de problemas: por una parte, aquellos propios de la transición, donde hace referencia al dilema de la tortura (qué hacer con aquellos funcionarios militares que estuvieron vinculados con violaciones a los derechos humanos) y al dilema pretoriano (cómo establecer un modelo profesional de relaciones entre los civiles y los militares); por otra parte, nos habla de los problemas contextuales, en franca alusión a un conjunto de factores básicamente socio-económicos tales como la pobreza, la desigualdad, la deuda externa y los bajos niveles de crecimiento económico que, en su opinión sobreviven a los desplazados regímenes autoritarios; por último, menciona los problemas sistémicos a los que califica como aquellos derivados del funcionamiento del sistema democrático, no obstante, al llegar a esta altura del análisis, comenta que sobre los mismos no ahondará por considerarlos un "fenómeno de la postconsolidación". (Ramos, 2002, págs. 75,76 ) 
El concepto de democracia es también retratado en el marco del derecho internacional latinoamericano, como principio de orden público, según el Comité Jurídico Interamericano:

El «ejercicio efectivo de la democracia representativa» establecido en la Carta de la OEA (Artículo 3.2) es un principio de orden público internacional del Derecho Interamericano o como le denomina el Comité Jurídico Interamericano un «principio de orden público regional americano interpartes», según el cual debe regirse la estructura política de los Estados. (Ramacciotti, 2009)

Una vez clarificado cuáles son los elementos de la democracia, cuyo cumplimiento y ejercicio adecuado le dan legitimidad a un régimen, habremos de analizar el caso Venezuela, haciendo un recorrido histórico y describiendo, durante cada periodo, las percepciones de los venezolanos respecto de algunos de esos factores. 
uaestio Iuris

vol.12, nº.04, Rio de Janeiro, 2019.pp. 532-562

DOI: $10.12957 /$ rqi.2020.40134

2. La percepción ciudadana sobre el chavéz-madrurismo en razón de la mayor o menor satisfacción con la democracia y sus elementos

\subsection{Nivel de satisfacción con la democracia en general y con el gobierno}

Para contextualizar nuestro objeto, se describe a continuación gráficamente el índice de satisfacción ciudadana con la democracia en Venezuela:

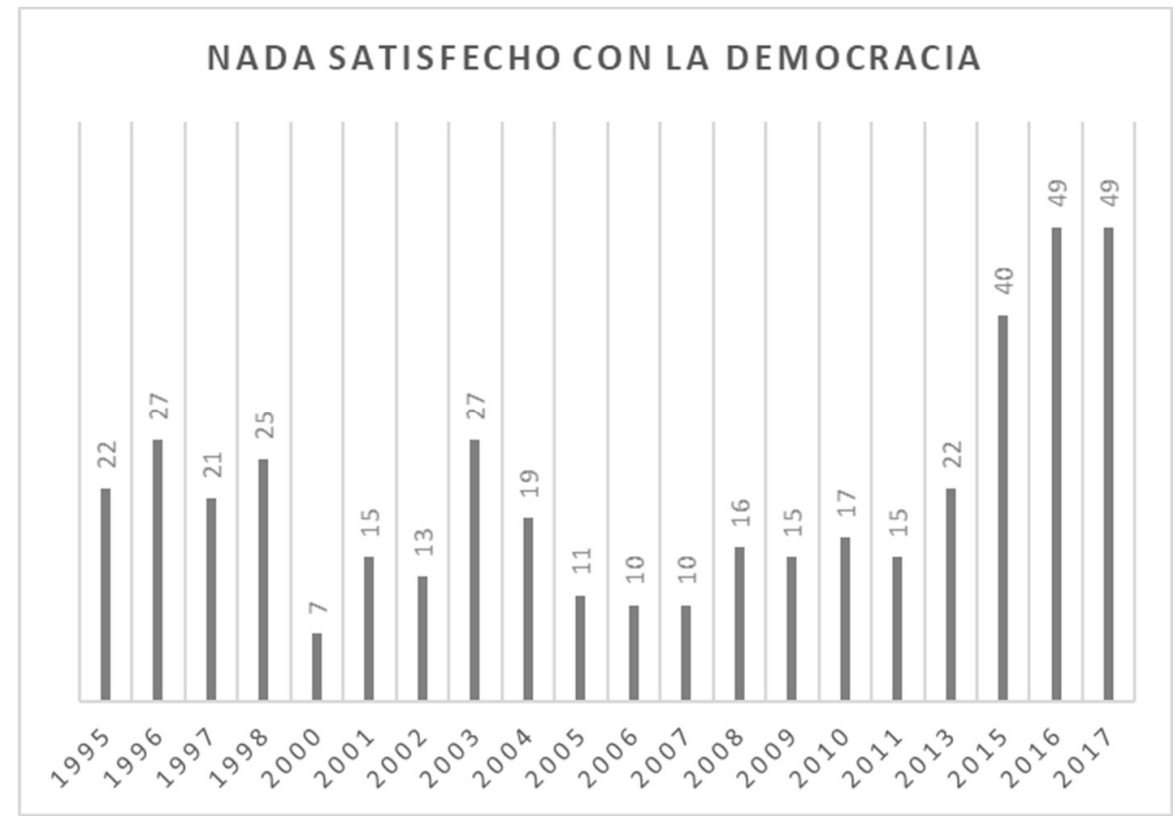

Gráfica 1; fuente. elaboración propia, con datos de latinobarometro.org 


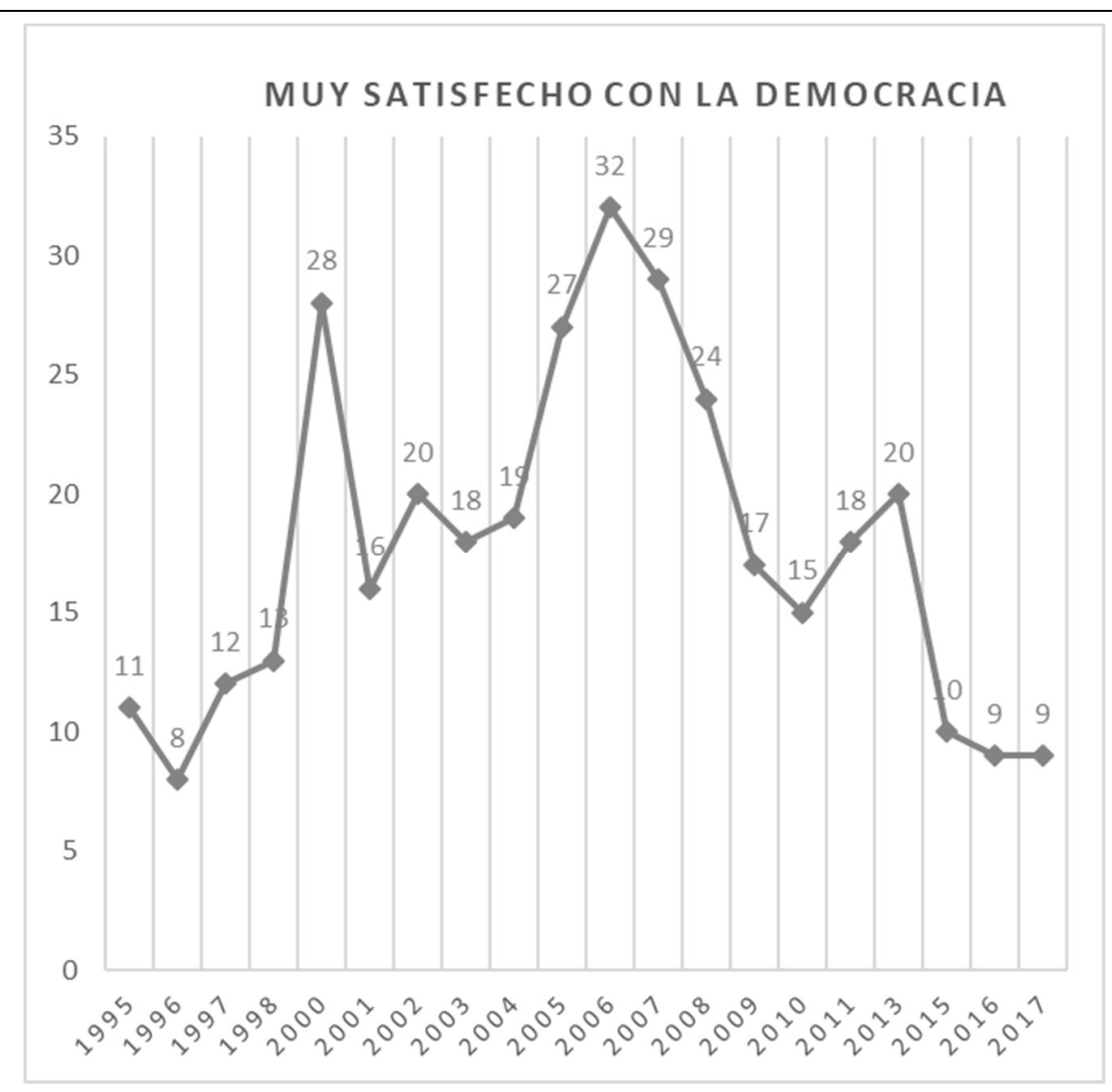

Gráfica 2, fuente: Elaboración propia con datos de latinobarómetro.org

Como se puede observar en el año 2000, un año después del acceso de Chávez al poder, (febrero de 1999), sólo un 7\% de los venezolanos está insatisfecho con el régimen, y un $28 \%$ está muy satisfecho; este es un buen año para el presidente que intentó un golpe de estado contra Carlos Andrés Pérez en 1992 lo que le costó, por cierto, dos años de cárcel. Sin embargo, un año más tarde, en 2001 el nivel de satisfacción se desploma a prácticamente la mitad, cayendo del 28 al 16\%. En este mismo sentido, el nivel de insatisfacción se eleva a más del doble pasando del 7 al 15 por ciento. De este desplome no se recupera sino hasta 2006, cuando los niveles de satisfacción se elevan hasta 32\% y los niveles de insatisfacción disminuyen al máximo en ese mismo año hasta un 10\%. Ahí se aprecia el pico más alto de satisfacción de todo el chavez-madurismo. ¿Qué pasó en 2000, 2008 y 2013 que provocó caídas pronunciadas en los índices de satisfacción ciudadana con la democracia? Es el fenómeno que pretendemos explicar.

En este mismo sentido se presenta la siguiente gráfica que demuestra que durante el régimen existe actualmente una crisis de confianza de los ciudadanos para con el gobierno, particularmente en 2003, y de 2015 a 2017: 


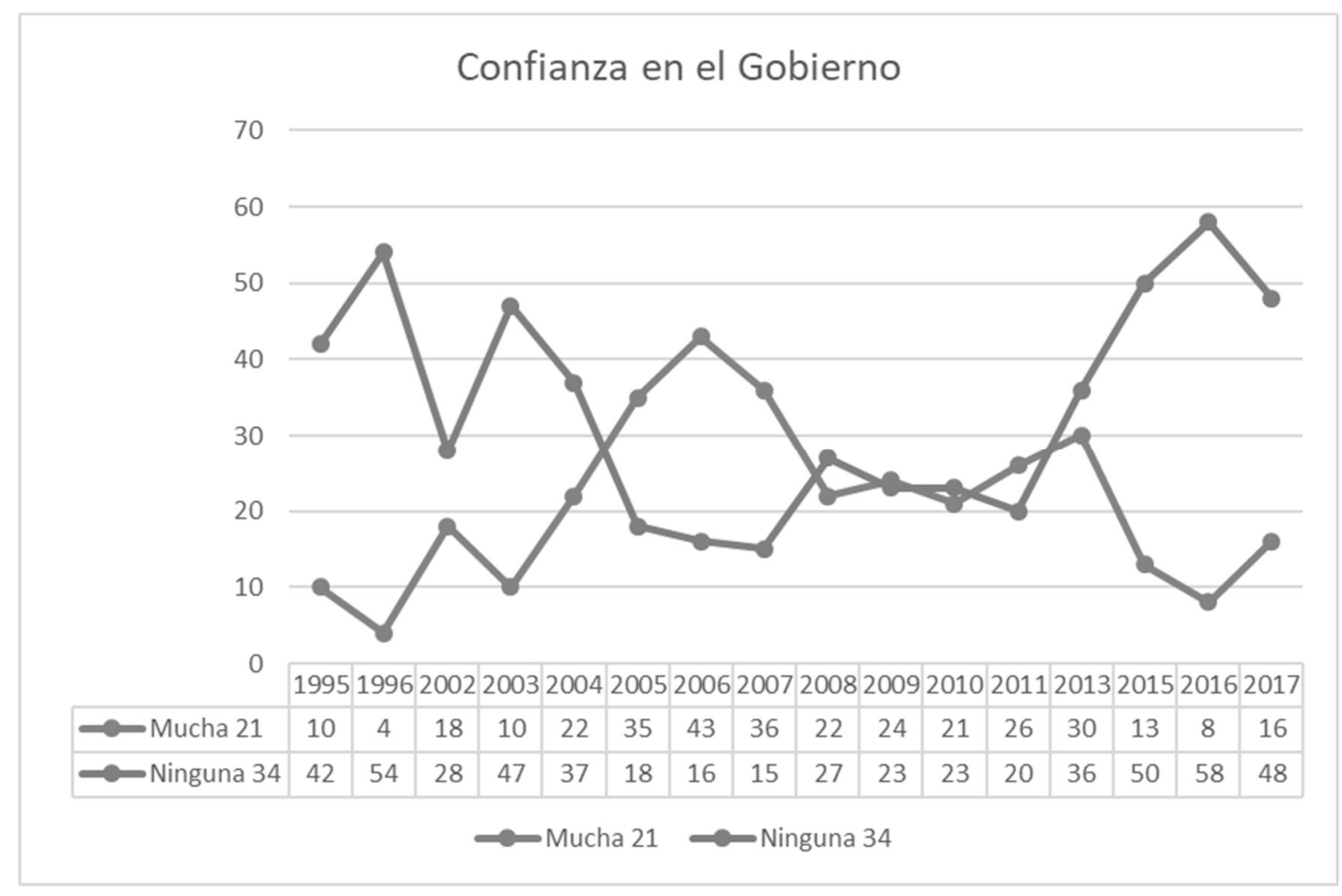

Gráfica 3; fuente. elaboración propia, con datos de latinobarometro.org

\section{A) La debacle del 2000 al 2004 en materia de satisfacción sobre la democracia}

El año 2000 fue para Hugo Chávez un espacio de prueba en el ámbito internacional, pues en mayo la OEA declaró que no existían condiciones para que el proceso electoral fuera transparente -señalamiento que por cierto, en términos similares, se repitió en 2008-, pues en esas llamadas mega elecciones, el organismo internacional, del cual Venezuela es parte, "planteó siete requisitos para que las elecciones fueran trasparentes” (Ramos, 2002, pág. 91). En esas elecciones se cuestionó, según un informe de la OEA que “...se recibieron varias denuncias por parte de candidatos en diferentes estados, acerca de irregularidades durante el día de los comicios" (OEA, 2000).

El 2002 ha sido señalado como "el inicio de la distorsión de la transformación". Esta distorsión es comentada por Alan Brewer-Carías en los siguientes términos:

"las organizaciones y partidos de oposición consideraban que esta transformación inicial se había distorsionado, aduciendo que: «el clamor por el cambio en democracia basado en la 
reacción contra la exclusiva representatividad de los partidos tradicionales, la verdad es que ha sido marginado por la exclusiva representatividad de un partido político, el de gobierno». (Omaña, 2008, pág. 14)

Otro elemento a considerar durante 2002 es la denuncia sobre la alteración del orden constitucional. En abril de este año existió una conflictividad y polarización política en Venezuela, factores qué desencadenaron una alteración del orden constitucional que amenazó la subsistencia del sistema democrático:

"Para Margarita López Maya, una salida institucional, democrática, implicaba para Chávez rectificar, fortalecer las instituciones democráticas en la sociedad y el Estado que puedan servirle como base de apoyo, sin embargo, esta rectificación no se produjo y durante el año 2002 la crisis llegó a su punto máximo, provocando una ruptura del orden constitucional que por unas horas sumió a Venezuela en el caos institucional y amenazó la propia existencia del sistema democrático en el país. (Omaña, 2008, pág. 18).

Omaña se refería al golpe de estado contra Hugo Chávez, horas en las que se vivió una profunda crisis económica en ese país derivada de la crisis política. En este aspecto, la comunidad internacional tuvo una participación “ambivalente” según la interpretación de Batalla (2004), pues la OEA se limitó a administrar las consecuencias de los hechos, pudiendo dar origen a interpretaciones resultantes en la legitimación del nuevo gobierno.

“Así, aún condenando la ruptura del orden institucional, la resolución de la OEA no se pronuncia por el retorno del gobierno constitucionalmente electo. Una vez producido el regreso de Chávez, la OEA condena nuevamente el golpe, pero, asigna al gobernante parte de la responsabilidad por estimular una "excesiva polarización" en la sociedad venezolana. A partir de ese momento todos sus esfuerzos se dirigieron a la búsqueda de fórmulas de diálogo entre Chávez y la oposición.” (Batalla \& Ferro, 2004)

La OEA declaró, ante este episodio que se condena

"la alteración del orden constitucional en Venezuela, los lamentables hechos de violencia que causaron la pérdida de vidas humanas, instó a la normalización de la institucionalidad democrática, y envió una misión encabezada por el Secretario General para investigar los hechos y adelantar las gestiones que considerara necesarias para restablecer el orden constitucional” (OEA S. , 2011, págs. 59,60) 
En su declaración de junio de 2002 denominada Declaración sobre la Democracia en Venezuela, la OEA “reiteró su apoyo al diálogo nacional convocado por el presidente Hugo Chávez y el ofrecimiento de colaborar en el mismo en el marco de la Carta Democrática Interamericana y establecieron la denominada "Mesa de Negociación y Acuerdos". (OEA S. , 2011, págs. 59,60)

Durante febrero de 2003 la OEA emite la Declaración contra la Violencia por la Paz y la Democracia, mediante el cual, a pesar de los seis meses durante los cuáles hubo un clima de tensión, extrema polarización política y amplia movilización pública, se hizo un llamado a los diferentes actores de la sociedad para que "se estableciera un clima de paz, tolerancia y convivencia democrática en el país”. (OEA S. , 2011, págs. 59,60) y en mayo de 2003

"se llegó a un acuerdo para encontrar solución por la vía electoral, además, El 15 de agosto de 2004 la OEA envió una misión de observación electoral ante el referéndum revocatorio presidencial, el cual tuvo lugar de forma pacífica y ordenada. No fue sino hasta agosto de 2004 cuando a través de un referéndum revocatorio, sucedió confirmación del presidente Chávez en la presidencia de Venezuela. (Ramacciotti, 2009, pág. 203)

\section{B) La efímera recuperación Chavista nunca más repetida}

De acuerdo con las gráficas 1 y 2, a partir de 2005 se empezó a recuperar la confianza de la ciudadanía y en 2006 es cuando el régimen de Chávez encuentra su máximo nivel de aceptación en cuanto apoyo popular, sin embargo, como se muestra en los datos de latinobarometro.org, fue sólo por esos dos años, pues en 2007 empieza la nueva debacle que le llevaría a Hugo Chávez a tener sólo un 15 por ciento de confiabilidad en materia de democracia en 2010 y a subir sólo un poco, hasta 20 puntos de aceptación en el año de su muerte en 2013.

Esta recuperación se da a pesar de los señalamientos de la oposición de parcialidad en las elecciones de 2005, relatada por freedomhouse.org en los siguientes términos:

"Las elecciones para la Asamblea Nacional en diciembre de 2005 dieron como resultado una legislatura completamente progubernamental luego de que los partidos de la oposición boicotearan las urnas debido a la percepción de parcialidad por parte de las autoridades electorales. En diciembre de 2006, el presidente Hugo Chávez fue reelegido fácilmente después de una campaña en la que la mayoría de la oposición decidió participar a pesar de continuas dudas sobre la conducta de los funcionarios electorales. En las semanas posteriores a su reelección, Chávez anunció que todos los partidos progubernamentales se fusionarían y 
que no se renovaría la licencia de la estación de televisión opositora RCTV." (freedomhouse.org, 2007)

\section{C) El inicio de la nueva caída de Hugo Chávez}

La organización Freedom House, la cual se autodefine como una institución que trabaja para defender los derechos humanos y promover el cambio democrático con un enfoque en los derechos políticos y las libertades civiles, ofrece una lectura de las elecciones de 2008 mismas que se caracterizaron "por descalificaciones motivadas políticamente de los candidatos de la oposición y el abuso de los recursos del Estado". (freedomhouse, 2018)

Este mismo año es descrito por Jácome (2010) como el periodo del desmantelamiento de los poderes locales y regionales que, emergidos desde la oposición, fueron maniatados por el gobierno de Chávez:

"La Constitución de 1999, enumera claramente las funciones y competencias de los gobiernos municipales y estadales. No obstante, el poder ejecutivo, mediante decretos y a través de modificaciones legales realizadas por la Asamblea Nacional, ha desarrollado una estrategia de reversión de muchas de estas competencias el poder central. En términos presupuestarios también se ha buscado disminuir sus recursos, de esta forma debilitando aún más a estas instancias. (Jácome, 2010, pág. 10)

\section{D) La debacle final de Nicolás Maduro}

Como se muestra en las gráficas 1 y 2, a partir de 2013, con el arribo de Maduro al poder, regresó la debacle del régimen en la percepción ciudadana. Ese año la población está cada vez menos satisfecha con la democracia; se eleva la mala percepción a 22 puntos porcentuales, en 2015 sube a 40, en 2016 sube a 49 y se mantiene ese porcentaje en 2017. Por lo que hace al índice de satisfacción con la democracia, los resultados son inversamente proporcionales: en 2013 cae a 20 porciento, en 2015 baja a 10 y en 2016 y 2017 se mantiene en sólo un 9 por ciento de venezolanos que están satisfechos con la democracia en el país.

\section{E) Análisis temático-estadístico de los resultados del gobierno chávez-madurista a partir}

\section{del informe de Luis Almagro sobre Venezuela en la OEA}

En junio, 2016 el secretario general de la OEA Luis Almagro emitió un informe ante el Consejo Permanente de la OEA en relación con el estado general de cosas de Venezuela. A pesar de que el mencionado informe se ofrece a tres años de que Nicolás Maduro asume el poder, no podemos obviar la influencia del periodo de Hugo Chávez en la realidad de ese momento. Se presenta aquí un resumen temático y cronológico 
de los aspectos más relevantes de dicho informe, contrastados con los resultados de instrumentos demoscópicos:

\section{a) Aspectos económicos:}

Los niveles de pobreza no tienen precedentes pues el 76\% de los venezolanos vivieron en la pobreza en el 2015 y la población enfrenta una escasez de alimentos (82,8\% en enero de 2016$)$ y medicamentos sin precedentes en todo el país. Desde 2003, más de 150 productos alimenticios han sido puestos en la lista de precios fijos que ha establecido unilateralmente el Poder Ejecutivo. A continuación, una gráfica que muestra el índice de satisfacción con el funcionamiento de la economía en general:

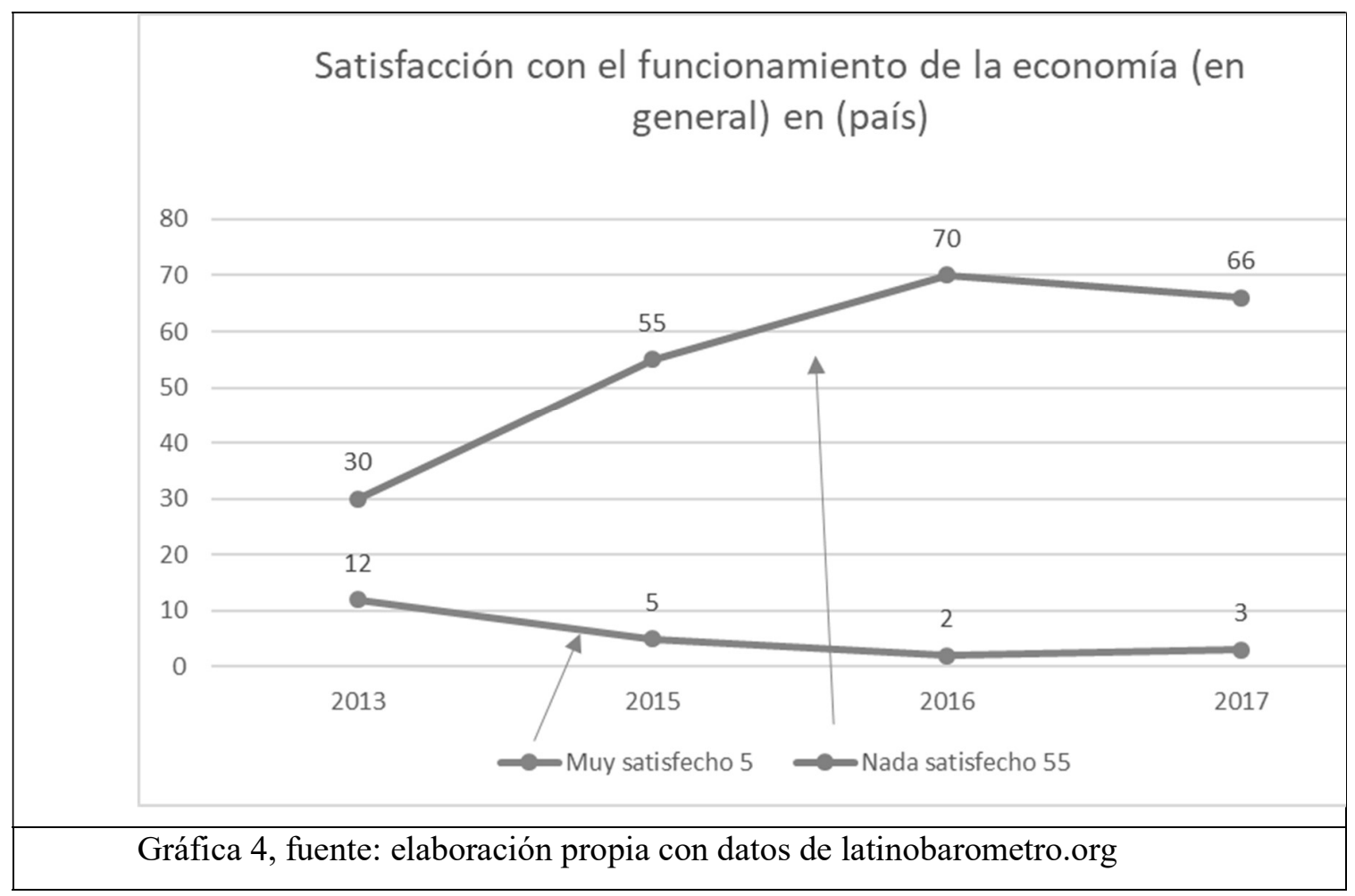

Como se observa, 2016 fue para los venezolanos el año más crítico en materia económica, subiendo de 55 por ciento a 70. Ahora bien, el salario mínimo equivale, de acuerdo a la tasa oficial, a 24 dólares, esto es menos de un dólar por día. Venezuela ocupa el noveno lugar mundial con la peor tasa de empleo lo que ha dificultado cada vez más el proceso económico en general, llegando a índices críticos en la facilidad para acceder a los productos de la canasta básica. 


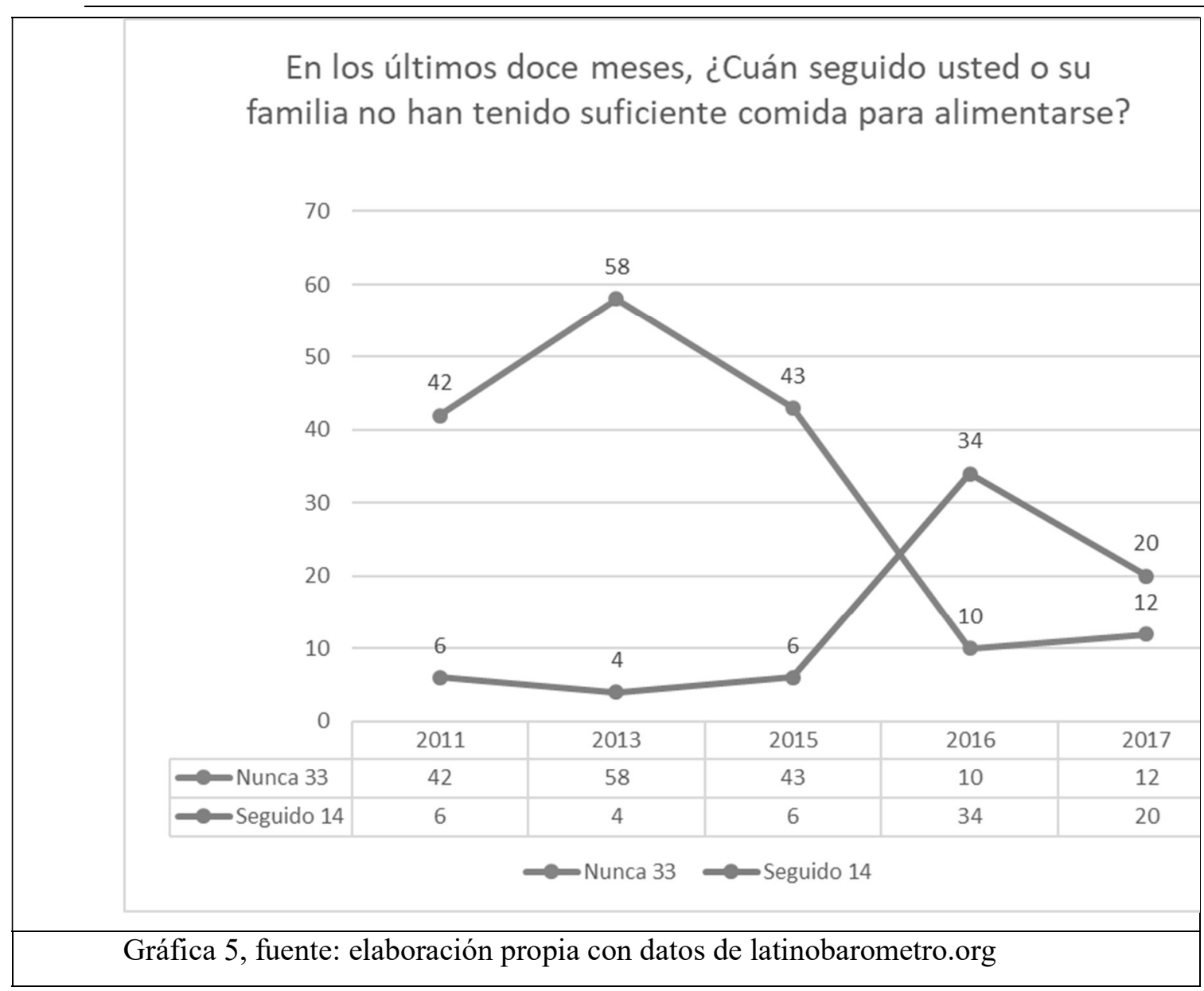

En la gráfica se observa cómo 2016 fue para los venezolanos un año crítico para acceder a insumos alimenticios básicos, pues de 6 por ciento en 2015, ha aumentado a 34 por ciento el índice de venezolanos que no ha tenido suficiente comida. Por otro lado, la inflación ha llegado a $720 \%$ y la moneda ha perdido el 99\% de su valor desde 2013, mientras que la deuda externa ha alcanzado los 130.000 millones de dólares, es decir, el equivalente de casi seis años de exportaciones de petróleo, según Almagro.

\section{b) División de poderes}

Para Perina (2012), la Alianza Bolivariana para los Pueblos de Nuestra América socava las instituciones, valores y prácticas democráticas pues promueve un patrón de comportamiento que pugna contra la separación e independencia de poderes, la libertad de expresión, el Estado de derecho, las elecciones libres y justas y el respeto de las minorías o de la oposición, entre otros - todas ellas consagradas en la Carta Democrática Interamericana. La autora plantea además que 
"En los últimos tiempos se han utilizado estas prácticas o una combinación de ellas en Argentina, Bolivia, Ecuador, Honduras (bajo Zelaya), Nicaragua, República Dominicana y Venezuela para asegurar el continuismo del nuevo «modelo» populista-autoritario. Inclusive, varios de ellos, siguiendo el liderazgo venezolano en la Alianza Bolivariana para los Pueblos de Nuestra América (ALBA), han comenzado a cuestionar la autoridad y legitimidad de la OEA, incluyendo sus instituciones de protección de los derechos humanos, el Tratado Interamericano de Asistencia Recíproca (TIAR) y las cumbres de Jefes de Estado. Este cuestionamiento refleja la fragmentación y división en que vive hoy el hemisferio. (Perina, 2012)

La misma autora afirma que, en su momento, el presidente Chávez actuó como si él fuera el estado, pues

"hay casos de abusos y distorsiones que ameritan un análisis colectivo sobre el estado de la democracia, algo que no puede considerarse intervencionista: en Ecuador, el presidente Correa expresó recientemente que como él es el Jefe de Estado, también preside los otros poderes del Estado; mientras que en Venezuela, el Presidente Chávez, actúa como si él fuese el Estado". (Perina, 2012)

En el mismo sentido, Jácome (2010) al citar a Ellner, puntualiza que desde sectores opositores se señaló que el gobierno de Chávez estaba concentrando el poder en manos del ejecutivo, restándole al legislativo funciones que había ejercido anteriormente, tal como las promociones de los militares, que se revertía la descentralización y que se le restaba restando autonomía al Banco Central de Venezuela.

En distintos periodos Hugo Chávez, este promovió diversas iniciativas ante el congreso la aprobación de leyes habilitantes, la de 2007 según Jácome (2007) disminuyó en forma significativa el papel de la Asamblea Nacional y la de 2010 provocó que el Secretario General de la OEA emitiera un comunicado en el que señalaba que dicha ley

"violaba la Carta porque despoja de poderes a la Asamblea Nacional entrante... El gobierno de Venezuela y sus aliados, que no permitirán el tratamiento del tema en la OEA, argumentan que la situación de Venezuela no solo refleja un proceso y orden democrático legitimado varias veces en las urnas, sino que es un asunto interno que no amerita ni reconoce injerencia externa de un organismo internacional (Perina, 2012) 
Otra circunstancia que demuestra que el régimen no ha respetado el principio de la división de poderes, es el hecho de que a fines de diciembre de 2015

"los miembros oficialistas de la Asamblea Nacional volvieron a copar el Tribunal Supremo designando a personas afines al gobierno, tan sólo días antes de que asumieran los legisladores opositores que habían triunfado en las elecciones legislativas del 6 de diciembre de 2015. (Vivanco, 2018)

Adicionalmente en 2016, de acuerdo con el informe presentado por Luis Almagro, Secretario General de la OEA,
"el ejecutivo repetidamente ha empleado intervenciones inconstitucionales en contra de la legislatura, con la connivencia de la Sala Constitucional del Tribunal Supremo de Justicia; después de los comicios del 6 de diciembre y antes de la instalación del período de sesiones de la nueva legislatura, 13 de los 32 magistrados y 21 suplentes del Tribunal Supremo prestaron juramento mediante nombramientos partidistas". (Almagro, 2016)

Ante esta realidad, también contamos con la opinión de Human Rights en 2017 sobre la división de poderes en Venezuela durante el periodo del presidente Maduro, púes en mayo de 2016 esta organización envió un análisis jurídico de sobre la aplicación de la Carta Democrática Interamericana en Venezuela al Secretario General Almagro de la OEA Luis Almagro en la cual establece lo que califica como una “evidente violación del principio de la separación de poderes y de la independencia judicial” en razón de un "nuevo copamiento político del Tribunal Supremo de Justicia", por lo que lo instan a implementar los mecanismos establecidos en la Carta Democrática para responder a las amenazas al orden democrático en este Estado Miembro. Esta instancia pide a la organización regional a invocar el artículo 20 de la Carta de la OEA a actuar sin el consentimiento del gobierno afectado para abordar
"una alteración del orden constitucional que afecte gravemente [el] orden democrático" de un Estado Miembro. Todo ello debido a que la Corte Interamericana de Derechos Humanos ha sostenido que "la independencia judicial y la separación de poderes son componentes esenciales del orden democrático". En este sentido hace una sentencia respecto de la inexistencia de la separación de poderes lo que ha propiciado "una variedad de graves abusos a los cuales no se les ha puesto ningún freno”. (Human Rights, 2016)

En el mismo sentido, durante 2017, la Unión de Partidos Latinoamericanos condenó la eliminación del poder legislativo y la asignación de facultades especiales a Nicolás Maduro en materia penal, militar, económica, social, política y civil. (Unión de Partidos Latinoamericanos, 2018) 


\section{c) Derechos humanos}

Afirma Almagro que el sistema de salud en Venezuela enfrenta serios problemas respecto a equipos, doctores, medicinas. En la siguiente gráfica se muestra como en 2016 los índices de satisfacción con la salud han caído dramáticamente hasta un 5 por ciento:

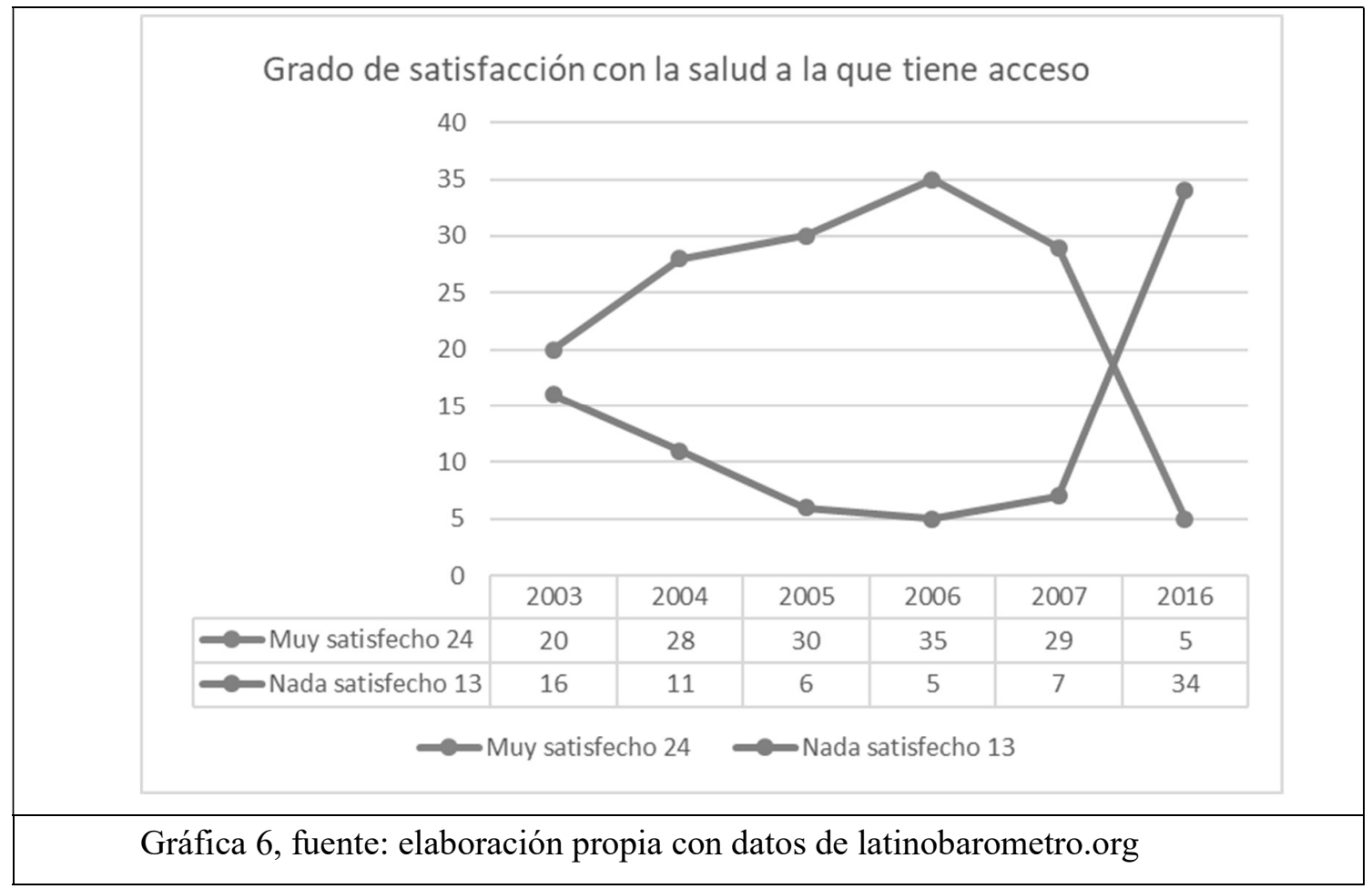

El Secretario General de la OEA también ha señalado que, en Venezuela, los medios de comunicación independientes son sujetos regularmente a procedimientos penales y administrativos, a la prohibición de viajar, a censura indirecta y al acoso. La Gráfica 7 muestra como en 2004 el 58 por ciento de los venezolanos consideraban que los medios de comunicación estaban frecuentemente influenciados por poderosos, la tendencia se confirma en 2007 con 57 por ciento y aumenta a 67 por ciento en 2016: 


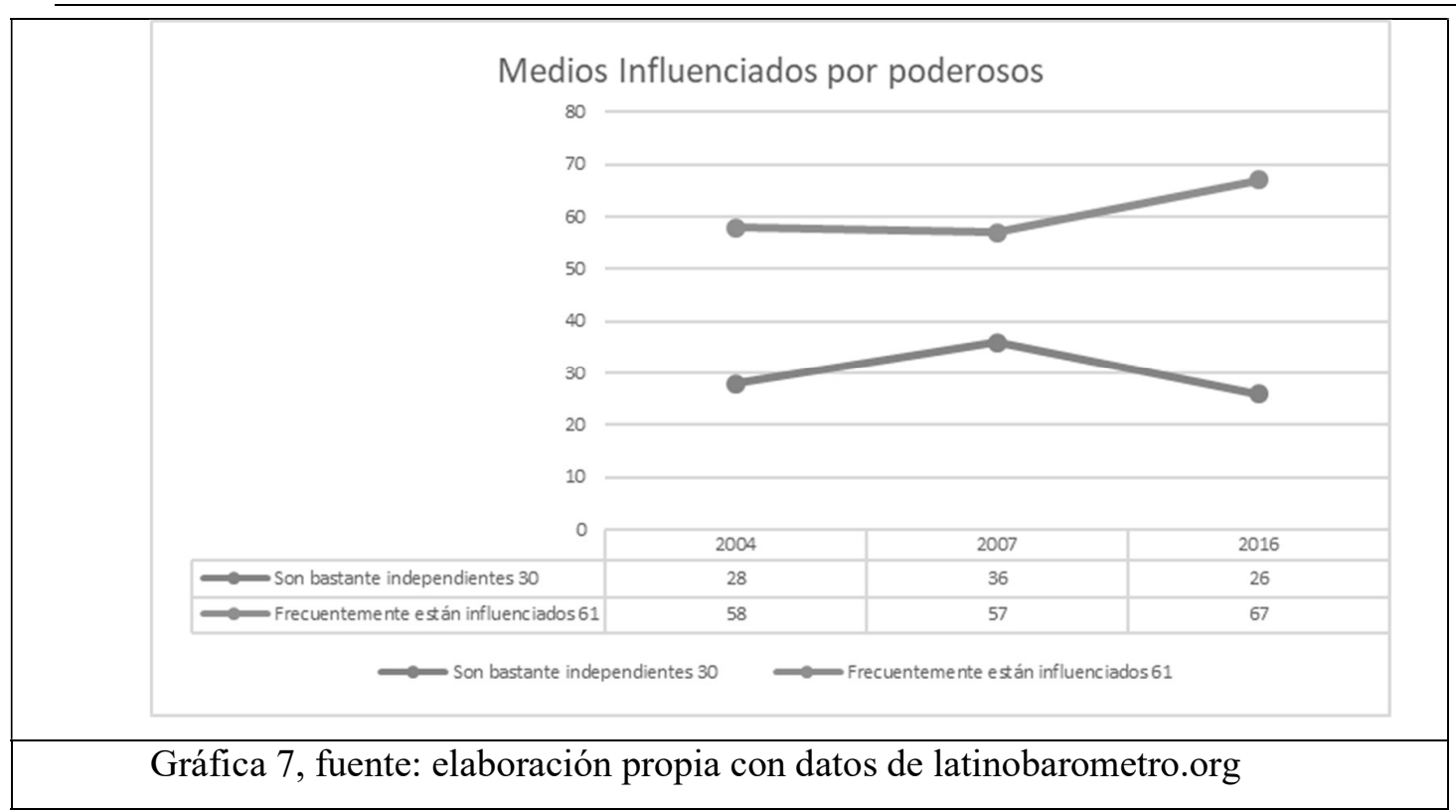

Según los datos ofrecidos por la multicitada fuente, en 2013, cuando el presidente Nicolás Maduro asumió el cargo, según el Foro Penal Venezolano había 11 presos políticos; entre enero de 2014 y el 31 de mayo de 2016 se denunciaron al Foro 4,253 detenciones, arrestos o encarcelamientos; desde 2014 se han denunciado al Foro Penal Venezolano 145 casos de castigo cruel e inhumano, incluida la tortura.

Según un informe de Human Rights Hatch denominado "Arremetida contra opositores: Brutalidad, tortura y persecución política en Venezuela", se documentan 88 casos sobre al menos 314 personas, muchas de las cuales describieron haber sufrido graves violaciones de derechos humanos en Caracas y 13 estados entre abril y septiembre de 2017. (Human Rights, 2017)

En el mismo sentido Perina (2012), se refiere a los "detallados informes de la Comisión Interamericana de Derechos Humanos sobre violaciones de derechos y libertades políticas fundamentales ocurridos en Estados miembros que así lo ameritan son de la máxima pertinencia para la alerta temprana sobre situaciones que podrían terminar en una ruptura institucional. Los informes sobre Honduras, 2009 y 2010; Venezuela, 2009; Bolivia, 2009; Perú, 2000, Haití, 1991-1993, y Nicaragua,1978, muestran una relación explícita entre democracia y la vigencia o no de derechos humanos". (Perina, 2012)

Como plantea Hernández (2010), ante la violación de derechos humanos en Venezuela, en 2018 la fiscal de la Corte Penal Internacional (CPI) Fatou Bensouda, anunció el pasado 8 de febrero que se abrirá un 
examen preliminar sobre posibles violaciones a los derechos humanos y uso de fuerza excesiva por parte del gobierno de Nicolás Maduro, pues

“cuando las protestas llenaron las calles de Caracas de abril a julio del año pasado, 124 personas murieron, más de 10.000 resultaron heridas y aproximadamente 5000 personas fueron detenidas arbitrariamente, según el informe del Alto Comisionado de las Naciones Unidas para los Derechos Humanos. (Hernández, 2018)

\section{d) Estado de derecho}

En 2002, la Comisión Interamericana de Derechos Humanos en sus observaciones preliminares al culminar su visita a la República Bolivariana de Venezuela considera que existen en ese país una serie de debilidades y fallas en el estado de derecho en ese país, en los siguientes términos:

"Hay la falta de independencia del Poder Judicial, limitaciones a la libertad de expresión, el estado deliberativo en que se encuentran las Fuerzas Armadas, el grado extremo de polarización de la sociedad, el accionar de grupos de exterminio, la poca credibilidad de las instituciones de control debido a la incertidumbre sobre la constitucionalidad de su designación y la parcialidad de sus actuaciones, la falta de coordinación entre las fuerzas de seguridad, representan una clara debilidad de los pilares fundamentales para la existencia del Estado de Derecho en un sistema democrático en los términos de la Convención Americana y de la Carta Democrática.” (Omaña, 2008 , pág. 16)

Parte de las consideraciones en torno al estado de derecho, es la incidencia delictiva. Según Almagro, Venezuela tiene uno de los más altos índices de delincuencia en el mundo: en 2015, el número de muertes violentas fue superior en Venezuela que el registrado en Afganistán, de acuerdo a cifras internacionales es el segundo país más violento del mundo. La siguiente gráfica nos muestra que, salvo 2015, de 2009 a 2017, los venezolanos tienen la percepción de que han sido víctimas de un delito: 
Quaestio Iuris

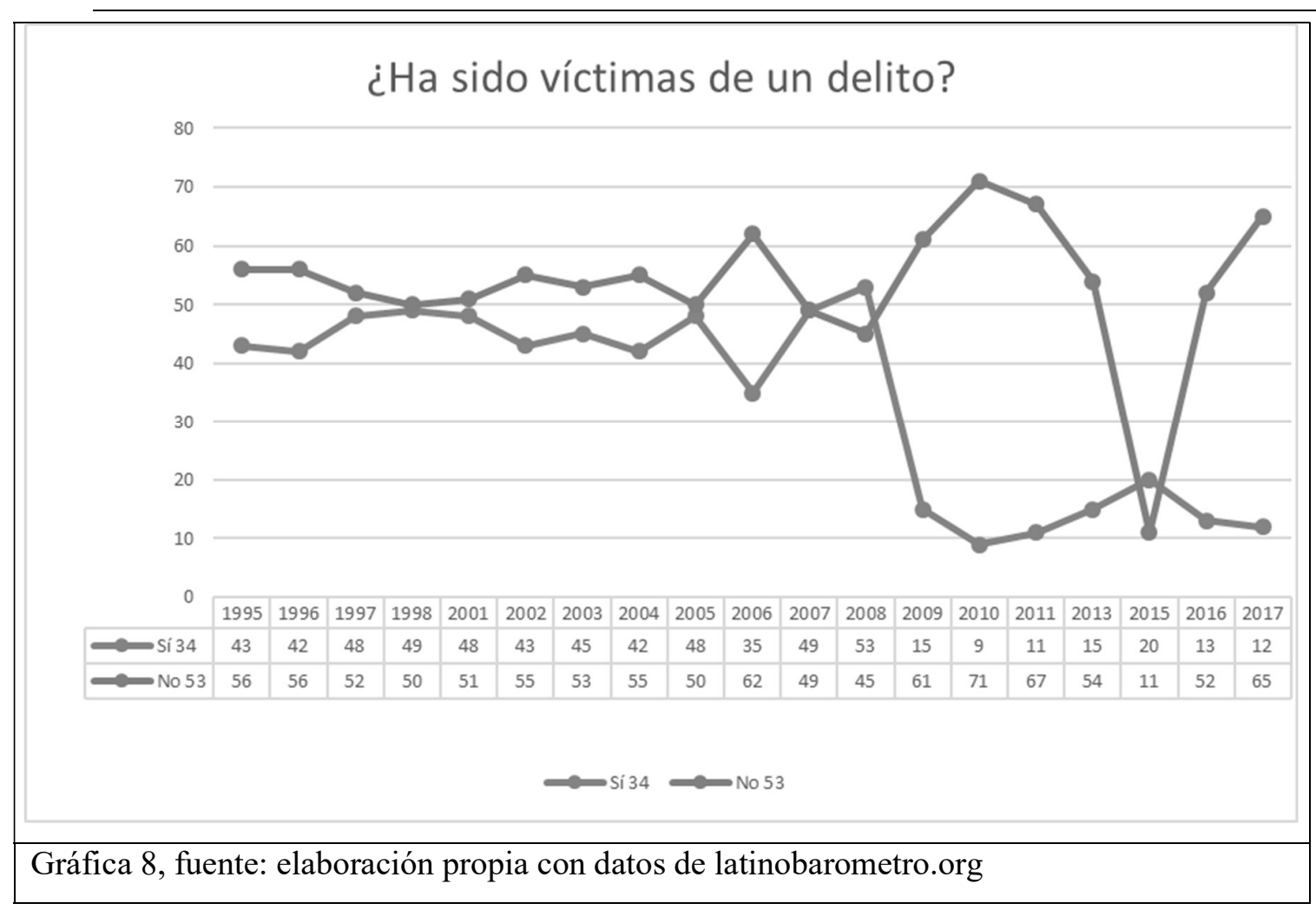

Otro índice importante en materia de estado de derecho es el relativo a la corrupción. Almagro en su informe establece que Transparencia International clasifica a Venezuela en el lugar 158 entre 168 países evaluados en lo que se refiere a la corrupción. Esta es la posición más baja en el continente americano. La gráfica 9 es explícita en referir que el 71 por ciento de los venezolanos consideraba en 2016 que el nivel de corrupción en su país aumentó mucho: 


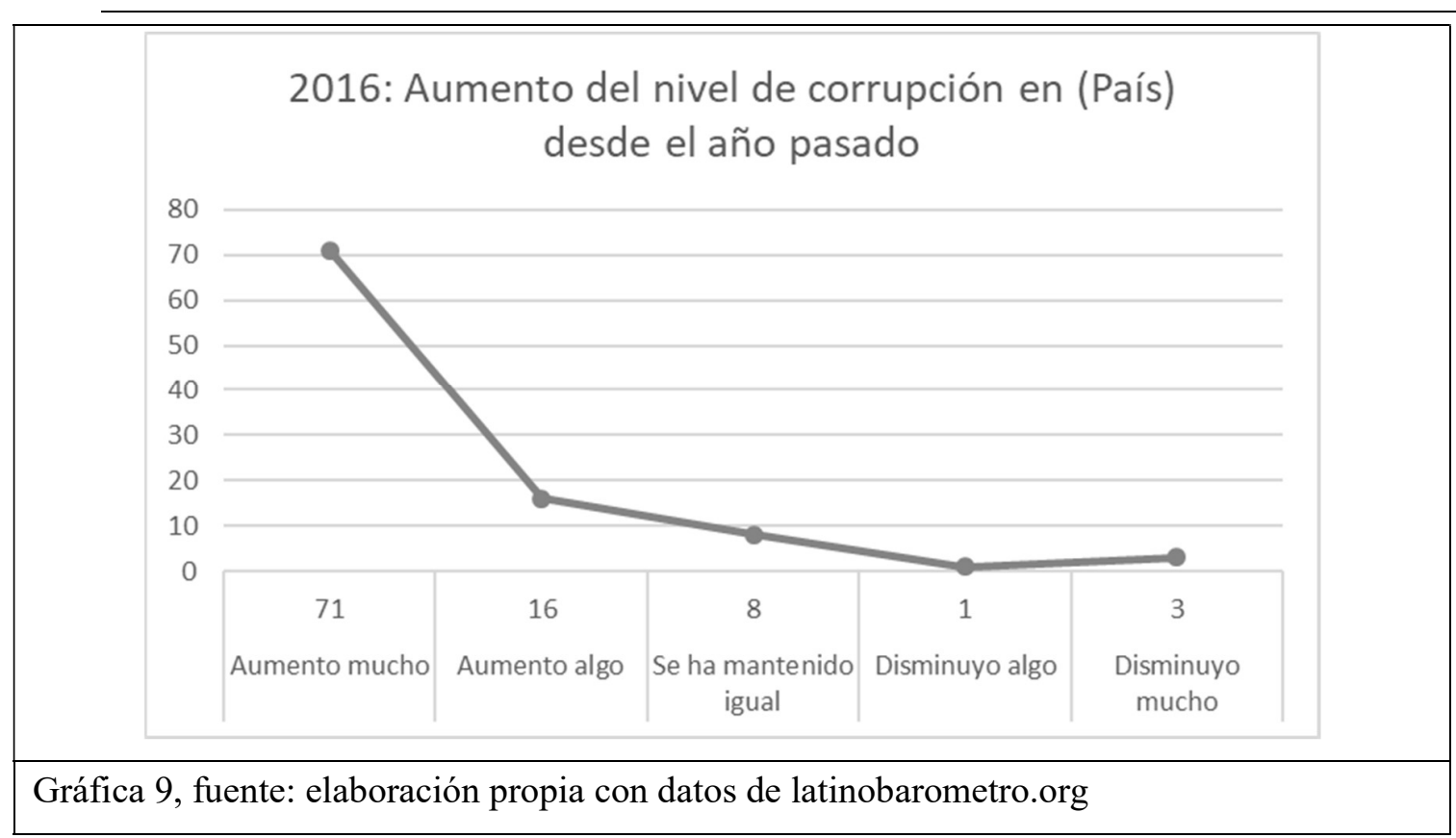

\section{e) Democracia, elecciones y partidos políticos}

Hasta 2013 sólo el 4 por ciento de los venezolanos consideraban que su país no era completamente democrático, mientras que en los próximos tres años subió radicalmente hasta 24 por ciento en 2017. Al contrario, la percepción en el sentido de que el país era toralmente democrático bajo de 29 por ciento en 2013 a sólo el 15 por ciento en 2017: 


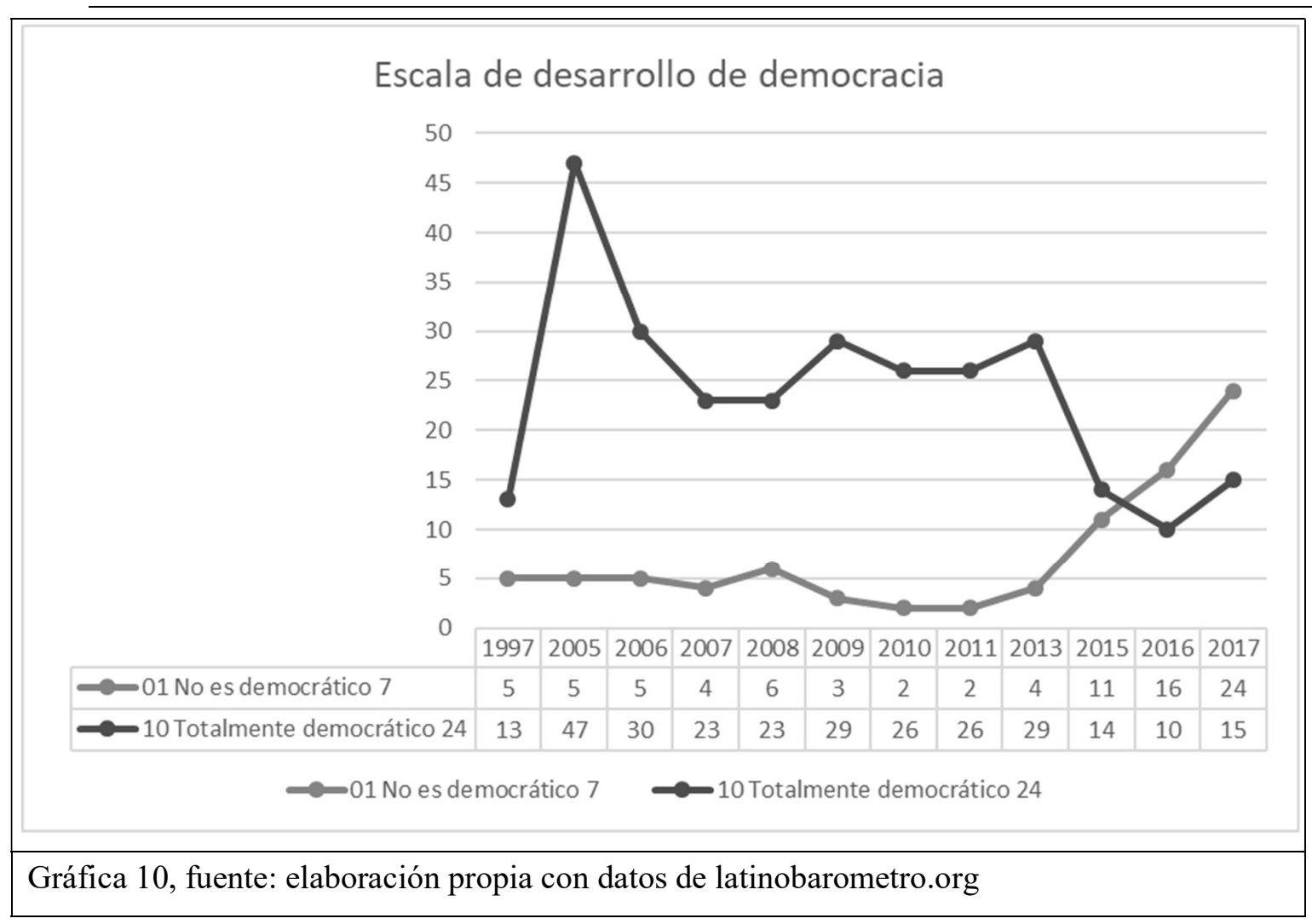

Hugo Chávez promovió la iniciativa de una nueva constitución en Venezuela en 1999, hecho que ha sido criticado desde la doctrina como una estrategia de fortalecimiento de liderazgos personalistas y con la clara intención de crear un partido hegemónico:

"Pese a que la Constitución de 1999 y el discurso oficial posterior ha privilegiado la democracia participativa, en la práctica se ha producido una tendencia hacia el desarrollo de un sistema político que gira alrededor del liderazgo del presidente Chávez y que tiende, más bien, a debilitar aún más a los sistemas partidistas. A ello cabe añadir la creciente militarización de la sociedad venezolano, a través de la Milicia Nacional Bolivariana y otras instancias que privilegian el discurso y actuación militar por encima de las instancias civiles. (Jácome, 2010, pág. 10)

El 23 de mayo de 2003 se firmó el “Acuerdo entre la Representación del Gobierno de la República Bolivariana de Venezuela y los Factores Políticos que lo Apoyan y la Coordinadora Democrática y las Organizaciones Políticas y de la Sociedad Civil que la Conforman", para encontrar una solución a la crisis del país por la vía electoral. El 15 de agosto de 2004 la OEA envió una Misión de Observación Electoral a 
fin de observar el Referéndum Revocatorio Presidencial, el cual tuvo lugar de forma pacífica y ordenada. (OEA S. , 2011, págs. 59,60)

La consecuencia en materia de percepción ciudadana de ese referéndum revocatorio -llamado así por la oposición y ratificatorio por el gobierno chavista - fue que el gobierno de Chávez subió repentinamente en el índice de confianza de la ciudadanía, pues según la grafica 10, el 47 por ciento de los ciudadanos consideraron al país como muy democrático, aumento que no se volvió a repetir nunca en todo el periodo Chávez-madurista pues a partir de esa fecha se aprecia una vertiginosa caída hasta el 15 por ciento en 2017. Está misma tendencia se observa en las gráficas 1 y 2, pues en 2006 sólo el 10 por ciento está nada satisfecho con la democracia y el 32 por ciento está muy satisfecho con la democracia. Se puede considerar a este periodo como la luna de miel chavista con el pueblo.

Otra de las grandes crisis democráticas en Venezuela es la de 2018. En este periodo se celebraron en mayo las elecciones presidenciales. Antes de la elección, el grupo de Lima integrado por 12 países latinoamericanos, dentro de los cuáles no se encuentra Venezuela, declaró que el gobierno de Nicolás Maduro imposibilita la realización de elecciones presidenciales democráticas, transparentes y creíbles, pues sin "la participación de todos los actores políticos venezolanos" sin “observación y estándares internacionales", esas elecciones carecerían de toda legitimidad y credibilidad. En ese sentido, exhortaron al Gobierno de Venezuela a que reconsidere la convocatoria de las elecciones presidenciales, subrayando que no puede haber elecciones libres y justas con presos políticos, sin la plena participación de los partidos políticos y líderes detenidos o inhabilitados arbitrariamente, con una autoridad electoral bajo el control del Gobierno, sin la participación de millones de venezolanos en el extranjero imposibilitados de votar, convocada originalmente por la asamblea constituyente, órgano carente de legitimidad y legalidad, cuya existencia y decisiones no reconocen. En un comunicado toma "nota del informe de la Comisión Interamericana de Derechos Humanos "Institucionalidad democrática, estado de derecho y derechos humanos en Venezuela", que documenta el serio deterioro de la vigencia de los derechos humanos y la grave crisis política, económica y social que atraviesa Venezuela", así mismo, toman nota de la decisión comunicada por la Fiscal General de la Corte Penal Internacional de conducir un examen preliminar sobre la situación en Venezuela sobre crímenes de lesa humanidad ocurridos en las protestas de 2017 (dw.com, 2018).

En un sentido similar, en abril 2018, la Unión de Partidos Latinoamericanos declaró no reconocer las elecciones presidenciales convocadas por el presidente Nicolás Maduro "por no cumplir con las 
condiciones de transparencia y observación internacional, lo cual hace imposible un proceso electoral democrático y constitucional. (Unión de Partidos Latinoamericanos, 2018)

En ese mismo sentido, en mayo de 2018, la Comisión Interamericana de Derechos Humanos, declaró que no existen condiciones mínimas necesarias para la realización de elecciones libres, justas y confiables y expresó su "profunda preocupación por la falta de condiciones mínimas necesarias para la realización de elecciones libres, justas y confiables en Venezuela”, por lo que llamó a realizar, "en plazo razonable y adecuado, elecciones sobre la base del pleno y efectivo ejercicio de los derechos humanos y principios democráticos". (OEA, 2018)

Ya concluidas las elecciones, el candidato opositor Henri Falcón, impugnó las elecciones señalando, entre otras irregularidades la compra de votos y el uso de los bienes del estado en la elección. Además, presentó un recurso para impugnar los comicios ante el Tribunal Supremo de Justicia (TSJ), en contra de la reelección de Nicolás Maduro, que obtuvo apenas seis millones de votos con una abstención del 53,98\%. (RTVE.es/EFE, 2018)

Un mes después de concluidas la elecciones, la OEA declaró que el proceso electoral de 2018 carece de legitimidad, que ha ocurrido "una alteración inconstitucional" y manifestó su decisión de "aplicar los mecanismos para la preservación y la defensa de la democracia representativa previstos en los artículos 20 y 21 de la Carta de la OEA" (OEA, 2018)

\section{Metodología del instrumento demoscópico empleado}

En su ejercicio 2016, latinobarometro.org plantea que los resultados provienen de un universo de población de 18 años y más; nivel de representación del 100\%, excluyendo del marco muestral poblaciones con densidad poblacional baja y zonas cuyo acceso es remoto; 1200 encuestas; error muestral de $2.8 \%$ (con un decimal); muestreo aleatorio poli-etápico por afijación proporcional a la población.

\section{Conclusiones}

Primera: La legitimidad de un gobierno va más allá de su legalidad, implica actuar de acuerdo a valores tanto en los medios como en los objetivos, contiene una dignidad supralegal que se levanta por encima de toda resolución jurídica, e incluso, debe contar con el consentimiento activo o pasivo de los gobernados reduciendo la proporción del empleo de la fuerza. La democracia material implica, además de un estado democrático, una sociedad democrática; y la democracia de funcionamiento implica que los gobiernos emanados de un proceso democrático deben actuar, además, con contenido democrático. 
Segunda: No existe un consenso en la doctrina sobre el orden, prioridad o importancia de los elementos para que el principio democrático se actualice en la sociedad, sin embargo, a fin de intentar una lectura consolidada que facilite el estudio, se presenta en cuatro grandes rubros una categorización de las múltiples ideas al respecto, sin obviar por supuesto, que existen diversos aspectos que pudieran considerarse como transversales por sus diversos puntos de contacto: a) Estado de derecho; gobernabilidad efectiva; adaptación del gobierno a una sociedad fraccionada debió al pluralismo de valores. b) Respeto a la voluntad popular: derecho al sufragio en elecciones libres, imparciales y frecuentes; alternancia en el poder, libre acceso a la observación electoral internacional, participación activa del ciudadano; ejercicio efectivo de la democracia representativa como principio de orden público; fomentar la racionalidad y la eticidad. c) Separación de poderes; ejercicio del poder legítimo, evitar el despotismo. d) Respeto a los derechos humanos; satisfacer las necesidades de las mayorías, libertad de la manifestación libre de las ideas; reconocimiento de la igualdad esencial entre los hombres; acceso a fuentes alternativas de información; respetar la autonomía de las asociaciones; ciudadanía inclusiva; solución de problemas socioeconómicos como la pobreza, la desigualdad, la deuda externa y los bajos niveles de crecimiento económico.

Tercera: Las conceptualizaciones y elementos esbozados en las dos primeras conclusiones, planteados en el ámbito de la teórica política como indispensables para que un gobierno sea legítimo y materialmente democrático, de acuerdo a las fuentes investigadas, no se actualizan durante largos periodos de tiempo del ejercicio del gobierno del chavez-madurismo en Venezuela, lo anterior se deduce de los dos grandes segmentos estudiados en el presente documento:

a) Los resultados de instrumentos cualitativos derivados de la doctrina y de los posicionamientos de organizaciones internacionales dan muestra de que en Venezuela se presentaron, durante el periodo analizado los siguientes fenómenos: procesos electorales no incluyentes y parciales por el uso de recursos públicos en favor de determinados candidatos, con falta de transparencia y con irregularidades; apuntalamiento del sistema unipartidista; desmantelamiento de los poderes regionales que no respondían al régimen; conflictividad y polarización política; ruptura del orden constitucional y del principio de división de poderes a través de la disminución de facultades y el copamiento de los poderes legislativo y judicial; caos institucional; altos niveles de pobreza; falta de insumos básicos para la salud y la alimentación; disminución del poder adquisitivo del salario y de las tasas de empleo; falta de aceptación de procesos de observación de organismos internacionales; procedimientos penales y censura e 
intervención hacia comunicadores que no coinciden con el régimen; aumento de la cantidad de presos políticos, tortura y persecución política; aumento de la incidencia delictiva y de corrupción.

b) Del instrumento cuantitativo analizado se concluye que del 2000 al 2004 existe un muy bajo nivel de satisfacción de la población con la democracia, a pesar de que en 2005 y 2006 el gobierno de Hugo Chávez tuvo un repunte importante, debido al refrendo constitucional, el presidente murió cuando el pueblo estaba sensiblemente insatisfecho con en esta materia. Por lo que hace al régimen de Maduro, desde 2013 hasta 2017 la caída libre en materia de satisfacción de la democracia fue imparable (Gráficas 1 y 2); la investigación arrojó bajos niveles de confianza en el gobierno del 2005 al 2007 y de 2015 a 2017 (Gráfica 3); se observa además que 2015, 2016 y 2017 son años en los que se eleva el nivel de insatisfacción con el funcionamiento de la economía en general (gráfica 4); en 2016 el 34 por ciento de la población considera que no tuvo suficiente comida para alimentarse y en 2017 llegó al 20 por ciento (gráfica 5); el porcentaje más alto de insatisfacción con el acceso a la salud se presentó en 2016 con 34\% (gráfica 6); igualmente en 2016 un porcentaje sin precedente manifiesta que considera que los medios de comunicación están influenciados por poderosos, el 67 por ciento (gráfica 7); 2009, 2010, 2011, 2016 y 2017 son años muy críticos en materia de percepción de los ciudadanos cuando consideran que han sido víctimas de un delito, para llegar en este último año a 65\% (gráfica 8); en 2016 se presenta un 71 por ciento de la percepción ciudadana en el sentido de que aumentó mucho el nivel de corrupción en el país (gráfica 9); en términos similares, durante 2016 y 2017, el índice de personas que piensan que su país es totalmente democrático disminuye dramáticamente al 10 y 15 por ciento respectivamente (gráfica 10). En la búsqueda de una constante se aprecian en general en todos estos factores, concomitantes con el principio democrático, dos momentos cuya incidencia negativa se repite, el periodo de inicio del gobierno de Hugo Chávez y todo el periodo del actual presidente de Venezuela Nicolás Maduro. 


\title{
Citizen perception of the democratic legitimacy of the regime chávez-madurista in Venezuela; international organizations and doctrine
}

\begin{abstract}
In order to infer whether the Venezuelan reality during the Chávez-Madurista period meets the parameters of legitimacy and democratic governability, in a demoscopic perspective of the same Venezuelans, the following assumptions were covered: a) description of the concept of legitimacy, as well as those of material, formal, origin and functioning democracy; b) distinction of citizen satisfaction indexes, in terms of the rule of law, division of powers, economy and human rights, based on the quantitative tools offered by latinobarómetro.org, contrasting the results with qualitative analysis of various instruments developed by Freedom House, Human Rights, the OAS, the IACHR, the UPLA and specialized academics' perceptions; c) in order to identify the causes of the statistical falls found, a list of historical facts that match temporarily with the application of the instrument was made, factual circumstances that, presumably, would explain the outcomes' reason. At the end of the process, the results point out that, in the specific case analyzed and from the point of view of the explained demoscopic perspective, the existence of the essential elements for the Chávez-Madurista government as legitimate and materially democratic is not updated, conclusion which is obtained abductively.
\end{abstract}

Keywords: Democratic governability, demographic studies, human rights, rule of law, division of powers.

\section{Bibliografía}

Almagro, L. (23 de junio de 2016). oea.org. Obtenido de

http://www.oas.org/es/acerca/discurso_secretario_general.asp?sCodigo=16-0050

Basave, A. F. (2000). Tratado de Filosofía. México: Limusa.

Batalla, I., \& Ferro, L. (2004). EL GOLPE DE ESTADO EN VENEZUELA DE ABRIL DE 2002 Y SU

PROYECCIÓN INTERNACIONAL. Universidad de la República, Montevideo.

Chile, M. d. (22 de Mayo de 2018). minrel.gob.cl. Obtenido de

https://minrel.gob.cl/minrel/site/artic/20180213/asocfile/20180213160223/v_d_lima_4_0.pdf

dw.com. (10 de octubre de 2018). Obtenido de https://www.dw.com/es/grupo-de-lima/t-41378602 
EFE. (2018). Venezuela acusa a la OEA de señalar su crisis para preparar una intervención.

WASHINGTON: El nuevo Herald. Obtenido de https://www.elnuevoherald.com/noticias/mundo/americalatina/venezuela-es/article210198334.html

freedomhouse. (22 de Septiembre de 2018). freedomhouse.org. Obtenido de https://freedomhouse.org/ freedomhouse.org. (2007). freedomhouse.org. Obtenido de https://freedomhouse.org/report/freedomworld/2007/venezuela

GARCÍA, D. S. (2006). EL CONCEPTO DE DEMOCRACIA EN DERECHO INTERNACIONAL. Revista Jurídica Universidad Autónoma de Madrid(ISSN versión electrónica 2174-0844 ). Madrid, España. Hernández, J. (14 de Febrero de 2018). ¿Por qué es buena noticia el examen preliminar de La Haya a Venezuela? New York, EUA. Recuperado el 30 de Julio de 2018, de https://www.nytimes.com/es/2018/02/14/opinion-corte-penal-internacional-venezuela/ Human Rights. (16 de Mayo de 2016). hrw.org. Obtenido de https://www.hrw.org/es/news/2016/05/16/carta-de-human-rights-watch-al-secretario-general-almagrosobre-venezuela Human Rights. (29 de noviembre de 2017). hrw.org. Obtenido de https://www.hrw.org/es/report/2017/11/29/arremetida-contra-opositores/brutalidad-tortura-y-persecucionpolitica-en

Insulsa, J. (2015). Gobernabilidad democrática, OEA 2005-2015. OEA. Jácome, F. (2010). EVOLUCIÓN/INVOLUCIÓN DE LA DEMOCRACIA EN AMÉRICA LATINA. (O. e. Ebert, Ed.) Caracas, Venezuela: Instituto Latinoamericano de Investigaciones Sociales (ILDIS) . Martínez, H. (2009). Los principios de la legitimidad política (Ferrero y los genios invisibles de la ciudad). Diálogos de saberes, 201-211.

OEA. (14 de Diciembre de 2000). http://www.oas.org. Obtenido de http://www.oas.org/sap/publications/2000/moe/venezuela/pbl_30_2000_spa.pdf OEA. (22 de Mayo de 2018). http://www.oas.org. Obtenido de http://www.oas.org/es/cidh/prensa/comunicados/2018/112.asp

OEA. (5 de junio de 2018). www.oea.org. Recuperado el 22 de Julio de 2018, de http://www.oas.org/es/centro_noticias/comunicado_prensa.asp?sCodigo=D-032/18

OEA, S. (2011). La Organización de los Estados Americanos: Paz, Democracia y Resolución de Conflictos. Washington, DC.

Omaña, R. (2008 ). La OEA en Venezuela, Entre la democracia y el golpe de Estado. Quito: Corporación Editora Nacional. 
Oro, L. (2002). LA IDEA DE LEGITIMIDAD EN MAX WEBER, CARLSCHMITT Y GUGLIELMO

FERRERO. Universidad Católica de Valparaíso, Santiago. Obtenido de

http://abacus.universidadeuropea.es/bitstream/handle/11268/5039/Oro_Tapia_2002.pdf?sequence=1\&isAll owed $=\mathrm{y}$

Perina, R. (2012). LOS DESAFÍOS DE LA CARTA DEMOCRÁTICA INTERAMERICANA. (I. d. Internacionales, Ed.) Estudios Internacionales 173, 7-36.

Ramacciotti, B. (2009). Democracia y derecho internacional en las américas. Cordova, Argentina: Lerner. Ramacciotti, B. (2009). Hacia un Derecho Internacional de la Democracia. Dialnet, 95-118.

Ramos, E. M. (2002). Democracia de la tercera ola en América Latina y el papel de la OEA. evista Venezolana de Análisis de Coyuntura, 65-98.

RTVE.es/EFE. (30 de mayo de 2018). El excandidato opositor Henri Falcón impugna los resultados de las elecciones en Venezuela. Venezuela. Recuperado el 30 de julio de 2018, de http://www.rtve.es/noticias/20180530/excandidato-opositor-henri-falcon-impugna-resultados-eleccionesvenezuela/1742326.shtml Unión de Partidos Latinoamericanos. (24 de Abril de 2018). uplalatinoamerica.org. Obtenido de http://uplalatinoamerica.org/?p=845\#more- 845

Vivanco, J. (2018). Human Rights Watch. Obtenido de www.hrw.org

\section{Trabalho enviado em 12 de fevereiro de 2019}

Aceito em 06 de fevereiro de 2020 